\title{
3D Morphometric Study of the Mandibular Fossa and Its Implication for Species Recognition in Homo erectus
}

\author{
Alon Barash ${ }^{1,2 *}$, Markus Bastir ${ }^{3}$, Ella Been ${ }^{2,4}$ \\ ${ }^{1}$ Faculty of Medicine in the Galilee, Bar Ilan University, Safed, Israel \\ ${ }^{2}$ Department of Anatomy \& Anthropology, Sackler School of Medicine, Tel Aviv University, Tel Aviv, Israel \\ ${ }^{3}$ Department of Paleobiology, Paleoanthropology Group MNCN-CSIC, Museo Nacional de Ciencias \\ Naturales-CSIC, Madrid, Spain \\ ${ }^{4}$ Department of Physical Therapy, Faculty of Health Professions, Ono Academic College, Kiryat Ono, Israel \\ Email: Allon.barash@biu.ac.il
}

Received 4 May 2015; accepted 7 August 2015; published 10 August 2015

Copyright (C) 2015 by authors and Scientific Research Publishing Inc.

This work is licensed under the Creative Commons Attribution International License (CC BY).

http://creativecommons.org/licenses/by/4.0/

(c) ()

\section{Abstract}

The problem of species recognition in paleoanthropology has been the subject of numerous studies. In the current study, we have used the complex topography of the mandibular fossa to assess its potential as a species-specific indicator. Six landmarks were registered using a microscribe 3Dx digitizer on four extant species: Pan paniscus, Pan troglodytes, Gorilla gorilla, and two ethnical groups of modern humans. Using principal component analysis (PC), the results statistically separated between the species and within the two Homo groups. The same method was applied to a sample of 13 casts of Pleistocene hominids from Asia, Europe and Africa. The first PC separated Asian Homo erectus from African Homo erectus and Homo heidelbergensis. The second PC separated African Homo erectus from Homo heidelbergensis. Interestingly Homo floresiensis groups with Homo heidelbergensis. Adding recent human sample to the analysis showed them to fall within the African Homo erectus group. Cluster analysis on the superimposed fossil data had turned the same results. These results favor the view that Homo erectus is actually made from at least two distinct species. Homo floresiensis is not a form of pathologic sapiens, and Homo sapiens has descendent solely from early African-like species.

\section{Keywords}

Homo erectus, Homo heidelbergensis, Homo ergaster, Morphometrics, Species Recognition

\footnotetext{
${ }^{*}$ Corresponding author.

How to cite this paper: Barash, A., Bastir, M., \& Been, E. (2015). 3D Morphometric Study of the Mandibular Fossa and Its Implication for Species Recognition in Homo erectus. Advances in Anthropology, 5, 152-163. 


\section{Introduction}

Species recognition is one of the most debatable topics in biology. Many studies had tried to define the nature of species and speciation processes (see Groves, 2001; Bruner, 2013). In paleoanthropology, where these issues are worsen by the loss of taxonomic characters (Tattersall, 1986, 2005), the problem is dealt by comparing known \& defined species' skeletal elements to an unknown or unassigned fossil hominoids (Argue et al., 2006; Kaifu et al., 2007; Curone \& Tobias, 2006; Susman \& de Ruiter, 2004). The use of distinct qualitative anatomical traits to distinguish between two closely related taxons may be problematic, as finding unique (autapomorphic) characters that separates the species becomes a difficult task. Some of the traits, like keels, torui and protuberances, may be debatable as these may not appear the same to all eyes. The use of univariate metric methods also holds difficulties. As noted by Godfrey \& Marks (1991) "Univariate dimensions are likely to display considerable overlap among closely related species..." (p. 58). Some of the disagreements that had risen between studies about morphological traits and taxonomic affinities (Rak, 1986; Trinkaus, 2003; Ascenzi et al., 2000; Bruner, 2007) are in fact, due to different methods of analysis, as was noticed by Trinkaus (1990). Applying multivariate analysis is more useful in these cases, because it sums the degree of variations, variations that univariately are statistically insignificant. The mandibular fossa of the temporo-mandibular joint is topographically complex structure, and as such it posses many taxonomic characters. Each of these characters can be quantified and evaluated as unique trait and thus the fossa may be suited for taxonomic analysis. Because of its "hidden" anatomical location within the skull base and its solid build, the fossa is frequently present and complete in fossils (Durband, 2008) making this area easier to analyse without encountering missing data problem (Holt, 2000; Strauss, 2003; Couette \& White, 2010).

Most studies of the fossa, like Ashton \& Zuckerman (1954) milestone paper, and Durband (2008) are descriptive and not quantitative, while others used univariate-metric measurements such as Hinton \& Carlson (1979), Wish-Baratz et al. (1996) and Green (2005). This kind of data may still be problematic when attempting to separate two closely related species. Using 3D morphometric techniques (Richtsmeier et al., 2002; Lawing \& Polly, 2010) allows us to define more accurately the shape of an object, and thus bring much more analytical data.

\section{African, Asian \& European Homo}

Hominid fossil discovery in the $19^{\text {th }}$ century had led to immense controversies between anthropologists of the time. Neandertals were the first to be discovered in 1829 in Engis, Belgium. It took almost 34 years and the discovery of the Neander valley specimen for a new species to be assigned—Homo neanderthalensis—by William king in 1863, and many more years to establish its taxonomic uniqueness. The story of other Pleistocene hominids and their taxonomic relationships is even more complicated. Ever since the discovery of the first Homo erectus, its taxonomic status as a species has been controversial. The debate originated with the unearthing of the Trinil skullcap (Dubois, 1894), which was followed by the discovery of a long line of fossils found throughout the old world. It seems that almost every fossil that was dated to the middle Pleistocene and was not assigned as a Neandertal, a new taxon was given. Naming just a few, these include Sinanthropus pekinensis (Black, 1927; Weidenreich, 1943) from China, Homo soloensis (Oppenoorth, 1932), from Indonesia, Telanthropus capensis (Broom \& Robinson, 1949) from southern Africa. It was Franz Weidenreich at the $38^{\text {th }}$ meeting of the American Anthropological Association held in Chicago on 1939, which made the first attempt to group all these fossils into one variant species-Homo erectus (Weidenreich, 1940). This proposal was accepted by some authors, but the debate continued, and peaked at the 1983 Senckenberg conference where authors like Wood (1984), Stringer (1984) and Andrews (1984) suggested splitting the lineages into African and Asian species, based on proposed autapomorphic features, such as a sagittal keel, angular torus and supraorbital ridges that would separates the Asian from the African species. It was also suggested that the Asian lineage is an evolutionary "deadend" and that the origin of Homo sapiens is solely from the African Homo lineage. This view was against those of Kennedy (1991), Rightmire (1984, 1990), and Kramer (1993) that claimed that these features are either present in all lineages or they are the evidence of a polymorphic species. Along with these so-called "classic" Homo erectus finds, many other fossils of the same age, on one point or another, classified as Homo erectus, Homo heidelbergensis or archaic Homo sapiens. Examples of such fossils are Petralona from Greece (Kokkoros \& Kanellis, 1960), Dali from China (Wu, 1981), Broken Hill (now Kabwe) from Africa (Woodward, 1921) and Steinheim from Germany (Berckhemer, 1933). The ambiguity of these fossils dazzled many authors as can be noted in the work of Howells $(1980)$, Stringer $(1979,1984)$ and Rightmire $(1996,2004,2013)$, and left many of 
the Pleistocene hominids in a taxonomic waste basket and an undetermined taxonomic affinity. The discovery of the small bodied hominid from Liang Bua, Indonesia (Brown, 2004) caused similar taxonomic uncertainty (Argue et al., 2006) that ranged from pathologic Homo sapiens (Henneberg \& Thorne, 2004; Hershkovtiz et al.. 2007) to new species with erectus like features (Morwood et al., 2005; Baab, 2012) or even habiline like features (Gordon et al., 2008).

The shape of the mandibular fossa and its borders are very variable in all of the above fossils, as noted by authors like Picq (1984, 1990), Rightmire (1990), Martínez \& Arsuaga (1997), and Durband (2008). OH-9 for example, displays an impressively deep and narrow fossa (Figure 1(a)), while in KNM-ER 3733, the fossa is shallow and wide with an elevated medial wall (entoglenoid process) (Figure 1(b)). The Dali cranium exhibits a shallow and wide fossa but with a modest entoglenoid process (Figure 1(c)). In spite of these marked changes, the fossa attracted little attention. Delson et al. (2001) and Mowbray (2002) argue with Durband (2002) about the qualitative shape of elements (squamotympanic fissure and post-glenoid process) within the fossa. Martínez \& Arsuaga (1997) published a detailed description of the fossa but with very little quantitative analysis. Terhune et al. (2007) had measured the temporal bone morphology using 18 landmarks, including five landmarks within and around the fossa for species recognition in Homo erectus. Baab (2008) used the overall cranial shape with two landmarks within the fossa for the same purpose. Later on the fossa was used to predict feeding behaviour among primates (Terhune, 2011, 2013).

In the present study we have used multivariate analysis to examine the shape of the mandibular fossa of the temporo-mandibular joint in living human and nonhuman primates as species specific indicator, and its applicability to species recognition in pleistocene hominids.

\section{Materials \& Methods}

Three non-human primates species, Gorilla gorilla, Pan paniscus, and Pan troglodytes, where used, comprising of 34 specimens, 17 males \& 17 females for each species. Primates were studied at the Royal Museum for Central Africa, Tervuren, Belgium. This museum houses one of the largest African zoological collections, was acquired in the early 20th century from central Africa. Two groups of modern humans, native Israeli and Indian were also used consisting of 34 specimens, 17 males \& 17 females in each group. Human skulls are housed in the archeological collection of the Sackler Faculty of Medicine in Tel Aviv University. Some of the skulls are designated for the medical school, while others are from archaeological excavations throughout Israel. The total number of specimens used in the analysis was 170 specimens (Table 1). All specimens used in this study are adults, as was determined by presence of the 3rd molar teeth. For fossil material we used 13 Homo erectushigh quality casts (Table 2), made available from the cast collection of Prof. Yoel Rak in Tel Aviv University.

Six landmarks were digitized (Figure 2, Table 3) using a Microscribe 3D digitizer (Immersion Corporation). This device is an articulated digital arm used to capture 3D landmarks from a physical models. It is widely used in anthropological field \& laboratory research (Sládek et al., 2012; Gunz \& Bulygina, 2012). The Landmarks captured the complex topography of the fossa. They were chosen as either type I or II, according to Bookstein (1991). These type of landmarks, such as junction of suture or highest/deepest points on the skull are easy to
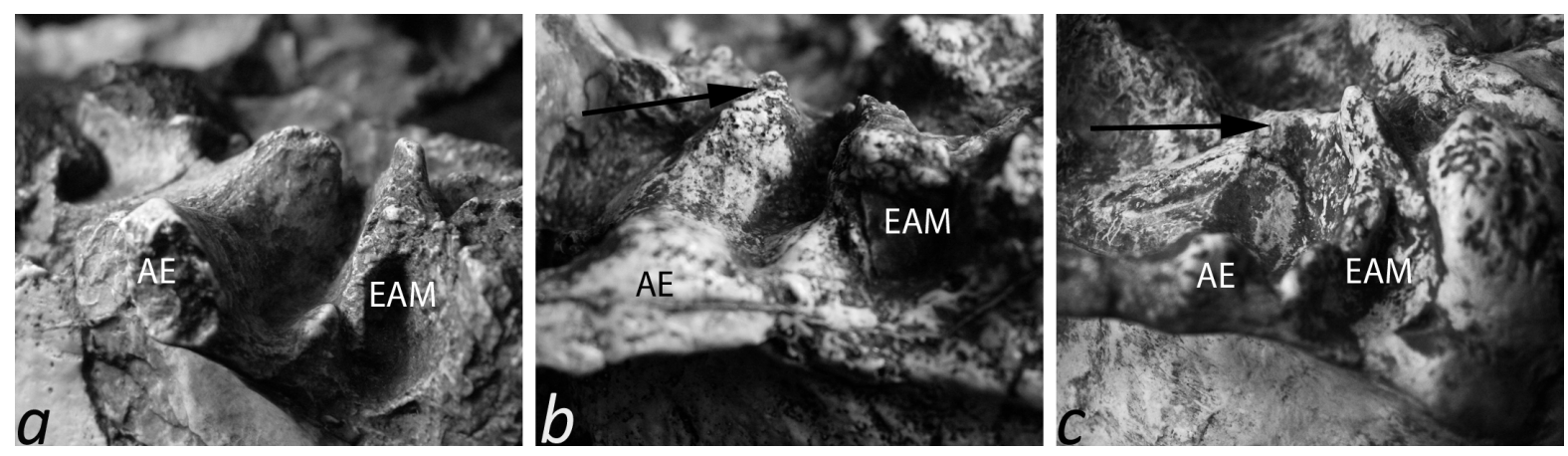

Figure 1. Mandibular fossa of three Homo erectus specimens in an oblique basal view: (a) OH 9 from Africa (note the deep fossa); (b) KNM-ER 3733 from Africa (note the shallow fossa and the elevated entoglenoid process, indicated by the arrow); (c) Dali from Asia (note the shallow fossa and the lack of entoglenoid process, indicated by the arrow. EAM, external acoustic meatus; AE, articular eminence. 
Table 1. Recent species list.

\begin{tabular}{|c|c|c|c|}
\hline \multicolumn{2}{|c|}{ Species/Group } & \multicolumn{2}{|c|}{ Source } \\
\hline \multicolumn{2}{|c|}{ Pan paniscus } & \multicolumn{2}{|c|}{ Royal Museum for Central Africa, Belgium } \\
\hline \multicolumn{2}{|c|}{ Pan troglodytes } & \multicolumn{2}{|c|}{ Royal Museum for Central Africa, Belgium } \\
\hline \multicolumn{2}{|c|}{ Gorilla gorilla } & \multicolumn{2}{|c|}{ Royal Museum for Central Africa, Belgium } \\
\hline \multicolumn{2}{|c|}{ Homo sapiens, Local Middle Eastern } & \multicolumn{2}{|c|}{ Tel Aviv University Osteological Collection } \\
\hline \multicolumn{2}{|c|}{ Homo sapiens, Indian } & \multicolumn{2}{|c|}{ Tel Aviv University Medical School Osteological Collection } \\
\hline Specimen name & Name used in study & Locality & Age (Ma) \\
\hline Petralona 1 & Petralona & Katsika Hill, Petralona, Greece & $\begin{array}{c}0.4-0.2 \\
\text { Grün (1996) }\end{array}$ \\
\hline Steinheim & Steinheim & $\begin{array}{l}\text { Sigrist gravel pit, Steinheim, Ger- } \\
\text { many }\end{array}$ & $\begin{array}{c}0.25 \\
\text { Adam (1985) }\end{array}$ \\
\hline Dmanisi 2280 & D2280 & Dmanisi, Georgia & $\begin{array}{l}1.7 \\
\text { Gabunia et al. (2000) }\end{array}$ \\
\hline Broken Hill 1 & Broken Hill & Kabwe, Zambia & $\begin{array}{c}0.4-0.7 \\
\text { Klein (1994) }\end{array}$ \\
\hline KNM-ER 3733 & 3733 & Koobi Fora, East Turkana, Kenya & $\begin{array}{c}1.78 \\
\text { Feibel (1989) }\end{array}$ \\
\hline KNM-ER 3883 & 3883 & Koobi Fora, East Turkana, Kenya & $\begin{array}{c}1.5 \text { - } 1.65 \\
\text { Antón (2003) }\end{array}$ \\
\hline KNM-WT 15000 & Nariokotome & $\begin{array}{l}\text { Nariokotome, West Turkana, } \\
\text { Kenya }\end{array}$ & $\begin{array}{c}1.5 \text { - } 1.65 \\
\text { Antón (2003) }\end{array}$ \\
\hline $\mathrm{OH} 9$ & $\mathrm{OH} 9$ & Olduvai Gorge, Tanzania & $\begin{array}{c}1.47 \\
\text { Manega (1993) }\end{array}$ \\
\hline Sangiran 17 & Sangiran 17 & Sangiran, Java, Indonesia & $\begin{array}{c}1.3 \\
\text { Antón \& Swisher (2001) }\end{array}$ \\
\hline Sangiran 2 & Sangiran 2 & Sangiran, Java, Indonesia & $\begin{array}{c}1.5 \\
\text { Antón \& Swisher (2001) }\end{array}$ \\
\hline Zhoukoudian 11 & CKN 11 & Zhoukoudian Cave, China & $\begin{array}{l}0.42 \\
\text { Antón \& Swisher (2001) }\end{array}$ \\
\hline Dali & Dali & Dali, Shaanxi Province, China & $\begin{array}{c}0.2 \\
\text { Rightmire (1998) }\end{array}$ \\
\hline
\end{tabular}

identify and repeat. In order to evaluate shape differences, the size, location and orientation of the fossa were removed from the data by superimposing equivalent landmarks using Generalised Least-Square (GLS) method (Rohlf \& Slice, 1990), thus leaving only procrustes residuals. Shape analysis was conducted using principal component (PCA), an extremely popular and widely used technique for statistical shape analysis (Bookstein, 1991; 


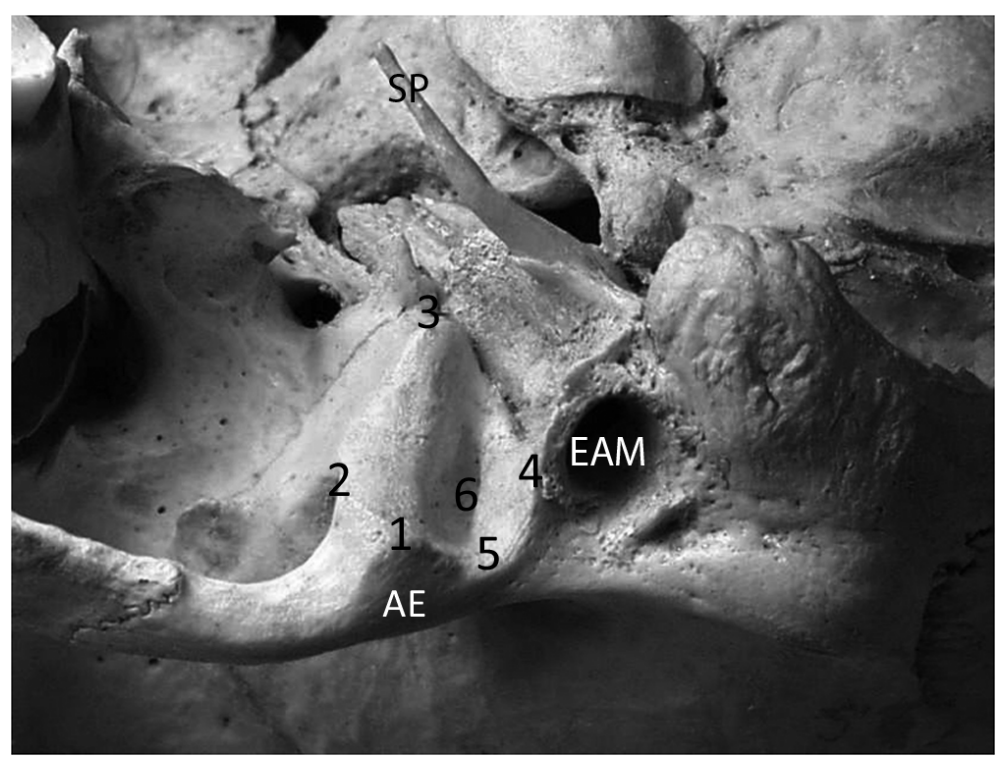

Figure 2. Landmarks used in this study numbered on a human skull, shown here in an oblique basal view. For a full description of the landmarks, see Table 3. EAM, external acoustic meatus; AE, articular eminence; SP, styloid process.

Table 3. Landmark definition. Skull is oriented in the anatomical position.

\begin{tabular}{|c|c|}
\hline Landmark No. & Definition \\
\hline 1 & Most inferior point on the lateral border of the articular eminence \\
\hline 2 & Most posterior point within the temporal fossa \\
\hline 3 & Junction of the squamotympanic fissure \& sphenosqamous suture \\
\hline 4 & Most inferior point of post-glenoid process \\
\hline 5 & Most superior point on the lateral border of the glenoid fossa \\
\hline 6 & Most superior point within the glenoid fossa \\
\hline
\end{tabular}

Dryden, 1998; Depecker, 2006 to name a few). This technique however requires a large sample size compared to the number of variables. The exact ratio between variables and sample size is a debatable subject (Osborne \& Costello, 2004), but a ratio of $4: 1$ has been quoted by several authors (Hatcher, 1994; Gorsuch 1983). It is therefore eminent to use as few landmarks as possible in order to be able to get valid statistical analysis, without losing the autapomorphic nature of the studied area. Superimposition process and the PCA were done using Morphologika 2.2 by O’Higgins and Jones (1998). ANOVA test was conducted on each PC in order to evaluate the statistical significance of the difference between studied groups. Two stages of analysis were conducted. The first step was to determine whether the fossa is a good indicator for species recognition. This was done by performing three analyses in order to evaluate the intra vs. inter specific variation. The first analysis was between the two Pan species, the second between the three ape species and the third added the two human groups to the apes. After demonstrating that species can be sorted based on the fossa, two analyses where conducted on the Homo erectus specimens. The first included the 13 casts of the fossils hominids. In order to assess the nature of taxonomic relationship between Homo sapiens and fossil specimens, the second analysis included the 13 casts and 4 recent humans. We further applied a cluster analysis of the superimposed data of the fossil specimens in order to determine the relationships between and within the different fossil groups. Cluster analysis was done using Ward's Linkage method (Ward, 1963). This method is extremely efficient when creating small clusters (Blackwood et al., 2003). The statistical analysis and cluster analysis was done by SPSS, Microsoft excel and PAST software by Hammer et al. (2001). 


\section{Results}

In all of the analyses, the first two components are related to inter-specific variation, while the third is related to intra-specific variation within modern human group only. Generally, the first component explains about 30\% of the observed variation; the second component about $20 \%$ and the third about $11 \%$. Overall, ten components explained more than $95 \%$ of the variation. No size, or sexual dimorphism correlation effect was observed while using more than one species in the analysis. In the following results we will only describe those components that were meaningful for our analysis.

The first analysis compares the two Pan species (Figure 3(a)). The first PC separates the two species explaining $30.2 \%$ of the variance in the data. The significance of separation is $P<0.005$. The second analysis adds the Gorilla to the two Pan species (Figure 3(b)). The first PC separates the three species and explains $29.5 \%$ of the observed variation. The separation between the gorilla and bonobo is $P<0.001$ while the separation between the two Pan species is $P<0.005$, as same as in the previous analysis. Interesting to notice, the Bonobo group falls between the Gorilla and chimpanzee. Next, the two human groups were added (Figure 3(c)). The first PC now separates between the apes and human and contributes $34 \%$ of the observed variation. The level of separation between the human and apes is $P<0.0001$. The second PC, separates between the three ape groups explains $18.8 \%$ of the observed variation, while the third PC (not shown here) separated between the two human groups explaining $11.7 \%$ of the observed variation. The level of significance of the separation between the apes remained the same as in the previous analysis with $P<0.001$ between gorilla and bonobo and $P<0.005$ between bonobo and chimp.

After establishing that the morphology of the mandibular fossa is useful for species recognition, we studied the fossil specimens. The first analysis included the 13 casts (Figure 4(a)). The first PC separated the Asian specimens including OH-9 from the European and African groups including Dali and LB1, and contributed 35.2\% of the observed variance. Asian specimens were separated from the two other groups with significance level of $P<$ 0.001. The second PC separated the European specimens, including Broken Hill, from the African specimens, including Dmanisi, and explained $24.1 \%$ of the observed variation with a significance level of $P<0.01$. Somefossils do not group geographically or spatially: The Dmanisi skull falls deep within the African specimens al-

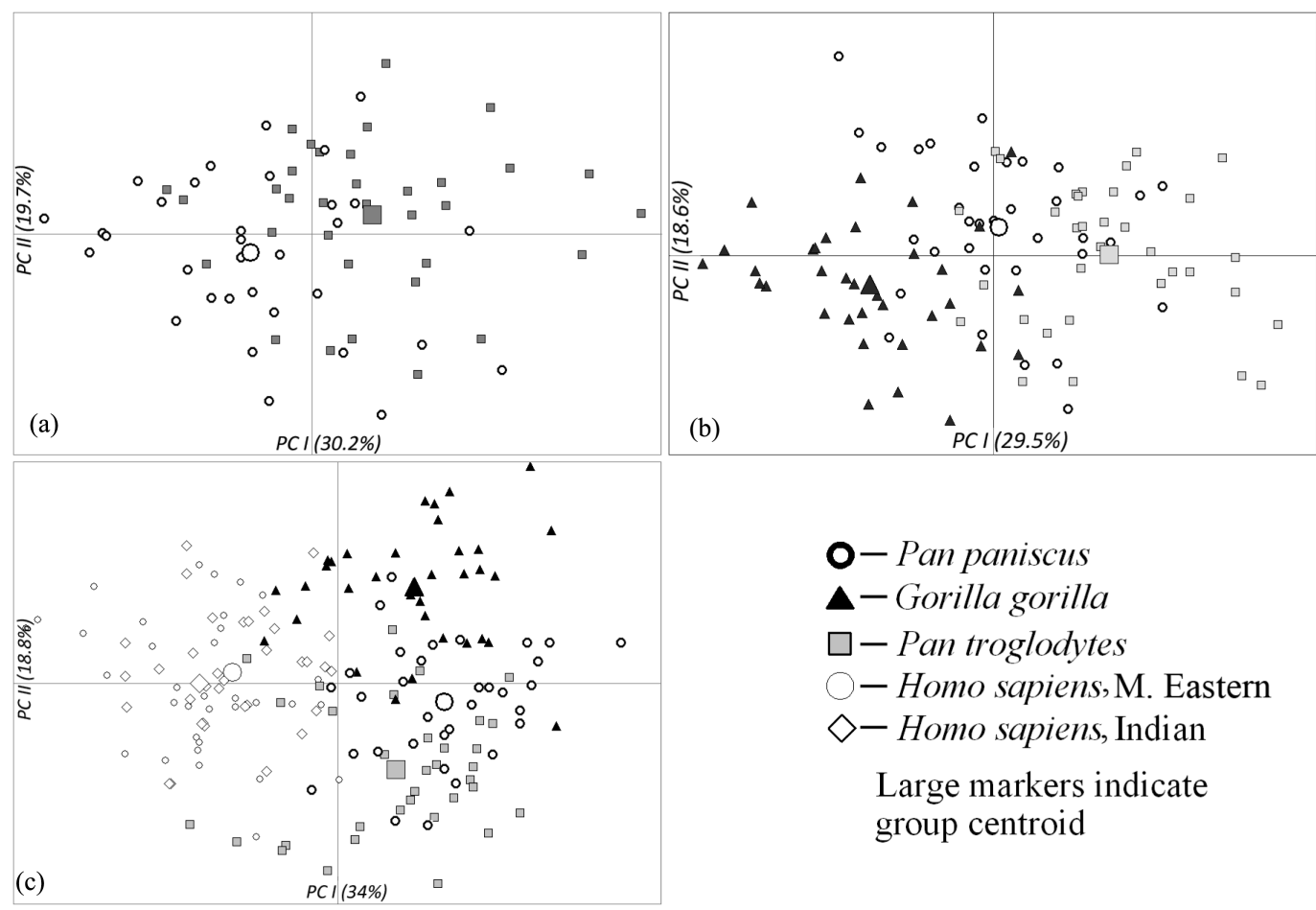

Figure 3. Principal component analysis of living species: (a) Analysis of the two Pan species; (b) Analysis of the three ape species; (c) Analysis of the two human groups with the ape species. Note that the relative position of each species is identical in all the graphs. 


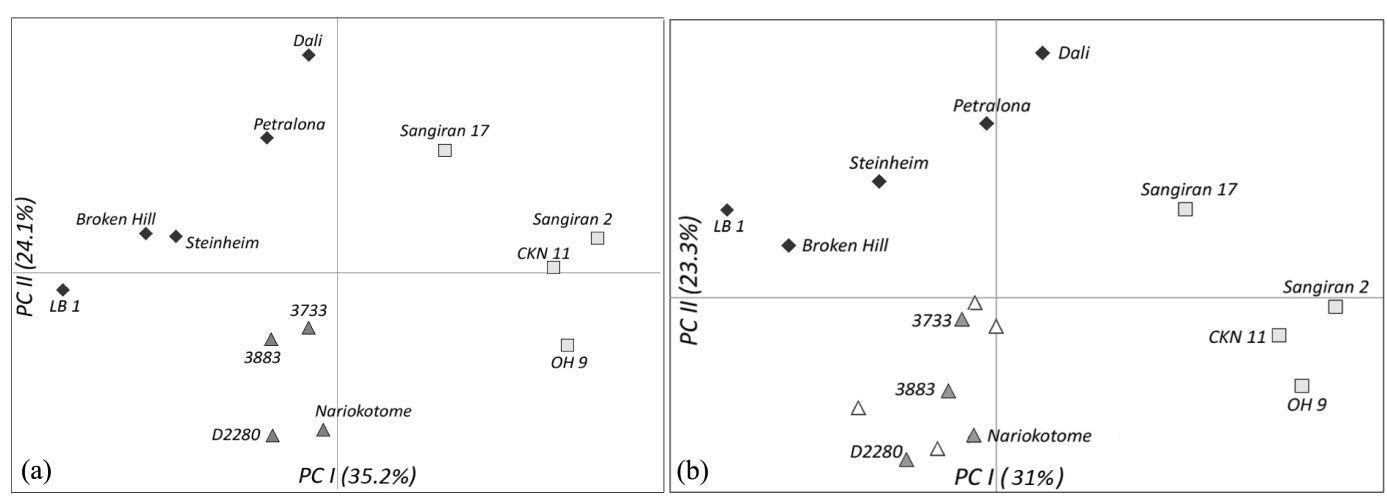

Figure 4. Principal component analysis of the fossil specimens: (a) Analysis of fossil specimens only; (b) Analysis of the fossil specimens with the added human group. Note the stable location of each specimen in both analyses.

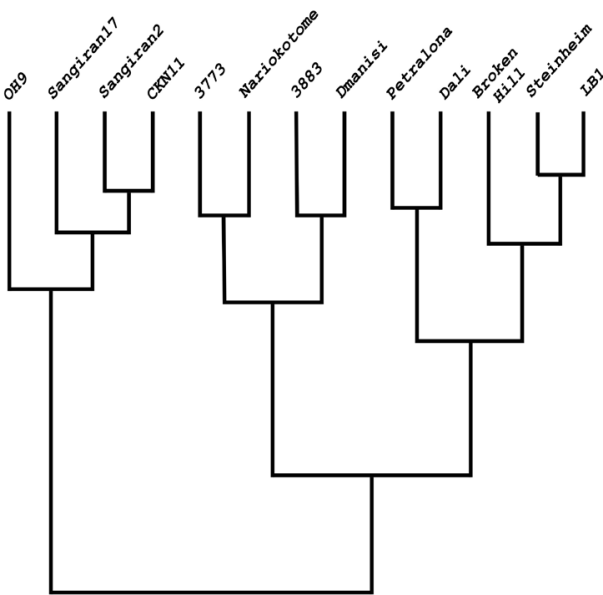

(a)

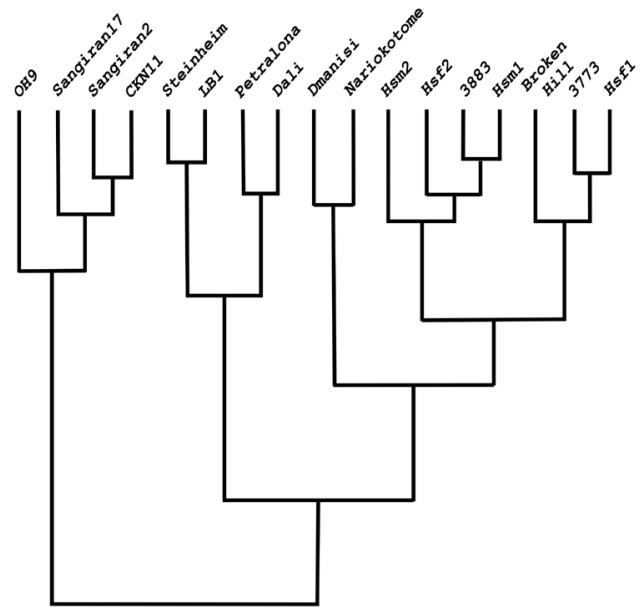

(b)

Figure 5. Cluster analysis using Ward's method: (a) Analysis of fossil specimens only; (b) Analysis of the fossil specimens with the added human group. Note the constant location of each specimen in both analyses.

though geographically very remote; The Dali skull from China falls close to Petralona from Greece; OH-9 falls in proximity with the Asian fossils although separated both geographically and temporally. Homo floresiensis seems to fall on the border between European specimens and African specimenscompletely opposite to other Asian material, and its closest neighboring fossil is Broken Hill, which is at least several hundred thousand years older and one of the most robust Homo skulls. In the second part of the analysis, four recent human specimens were added (Figure 4(b)). They consisted of two males and two females from the two human groups (randomly chosen). In this analysis all the modern humans fall well, and only, within the African specimens, while the fossils, with the exception of LB 1, retain their original position and their statistical significance, adding to the overall validity of the fossil analysis. The same procedure was repeated and returned the same results while using other recent human sample.

A cluster analysis of the fossils (Figure 5) was done on the superimposed data. The Asian group with $\mathrm{OH}-9$ is the most divergent cluster of the three, while African groupwith Dmanisi and European group with Dali exhibit greater similarity and a common ancestry. Homo floresiensis clusters with the Steinheim skull. The cluster analysis results are very similar to the ones obtained by the PCA, and thus further emphasise and increase the validity and the consistency of the results.

\section{Discussion}

This study used the morphometric attributes of the mandibular fossa as a method of differentiating between ex- 
tant \& extinct species. The use of small, confined and highly derived area is important to paleoanthroplogical studies, as these areas may increase our taxonomic understanding of the fossil record even when dealing with small, fragmentary pieces. In the first part of the analysis, it is clear through the extant species, that the fossa is indeed a good indicator for species recognition. The placement of the human group is opposite to the apes group; the bearing of the ape species is constant throughout the analysis whether humans are included or not. The level of significance of the separation between the different species is also constant throughout the analysis. These results generally coincide with previous works such as Lockwood et al. (2002), Terhune et al. (2007) and Harvati (2003), while using fewer landmarks over smaller area.

The second part of the analysis deals with the extinct species. Here, as expected the image is more complex. This is due to two main facts: first, the nature of fossils with their extensive timeframe and broad geographical distribution, which makes them more variable than extant species; Second, the relative small number of specimens, which lowers the statistical significance of the results. In spite of these shortcomings, few important and interesting aspects are visible. The first PC in the analysis separates Asian specimens including OH-9 from the African specimens including Dmanisi and European group including Broken Hill and Liang Bua. This might imply for an early separation of the two Pleistocene groups and suggests an African ancestry for the European group. The second PC separates European specimens including Dali from African specimens. Homo floresiensis seems to fall on the border between these two groups. Same results were evident from the cluster analysis.

These findings when compared to the extant species further corroborate and manifest that our analysis supports the proposition that at least three major different species existed in the Pleistocene: Homo heidelbergensis which expanded throughout the old world, Homo erectus from the Far East, a probable evolutionary dead-end and an African species that should be named Homo ergaster (after Groves \& Mazák, 1975), a species that was found throughout Africa and central Euro-Asia, and that is probably the sole ancestor to Homo sapiens. The results are further validated by analyzing the geographical and temporal dispersal of the different fossils: Dali from China and Petralona from Greece fall close together, although they come from very distant geographic areas. This result agrees with previous studies that affiliate Dali to Homo heidelbergensis (Rightmire, 1998). The Dmanisi skull falls deep within Homo ergaster group, especially close to Nariokotome, although separated by more than 4000 kilometres. Allocation of the early Dmanisi skull to Homo ergaster has been suggested by other (Gabunia, 2000; Baab, 2008; Lordkipanidze et al., 2013) although Terhune et al. (2007) found this specimen to have Asian origins. In our analysis $\mathrm{OH} 9$ falls close to the Asian Homo erectus, although it is an early African fossil (Leakey, 1961; Anton, 2003). An Asian affinity to this specimen was previously suggested by other authors (Clarke 2000; Anton \& Swisher, 2001; Terhune et al., 2007), although Baab (2008) assign it to the African lineage. Homo floresiensis, despite its recent age, and isolated geographical Javanese location (Brown, 2004) group with Homo heidelbergensis, especially close to the massive skull from Broken Hill, suggesting ancient taxonomic origin to this enigmatic specimen.

Our results does not suggest direct taxonomic ancestry between Homo heidelbergensis and Homo sapiens and contradict the notion of an "archaic" Homo sapiens.

Finally, we must bear in mind that our analysis does not necessarily limit the number of species to three. Considering the fact that the Homo ergaster specimens clusters with the human sample; the spacious clustering of the "classic" Asian specimens and Homo heidelbergensis; and the use of one area within the skull, the number of species may actually be greater than what appears from our analysis. It might turn, for example, that each of the following skulls OH-9, Sangiran 17 and LB1 represents an unknown or yet unassigned species.

\section{Conclusion}

In the present study, we have tried to use the morphology of the mandibular fossa as a species specific indicator for species recognition. Although we suspect our analysis will not be the final word, it does add to the growing evidence that supports the view that Homo erectus is not a single species, but represents a cluster of separate species in space and time, extending throughout the old world and across the Pleistocene. It seems that Homo sapiens have evolved solely from Homo ergaster or alike species probably in Africa. A closer examination of anatomical features of other skeletal elements, cranial as well as post-cranial, along with more hominids such as Homo habilis, Homo antecessor and Homo neanderthalensis, is needed to shed more light on this interesting stage of human evolution. 


\section{References}

Adam, K. D. (1985). The Chronological and Systematic Position of the Steinheim Skull. In E. Delson (Ed.), Ancestors: The Hard Evidence (pp. 272-276). New York: Alan R. Liss.

Andrews, P. (1984). An Alternative Interpretation of the Characters Used to Define Homo erectus. Courier Forschungsinstitut Senckenberg, 69, 167-175.

Antón, S. C. (2003). Natural History of Homo erectus. Yearbook of Physical Anthropology, 46, 126-169. http://dx.doi.org/10.1002/ajpa.10399

Antón, S. C., \& Swisher, C.C. (2001). Evolution and Variation of Cranial Capacity in Asian Homo erectus. In E. Indriate (Ed.), A Scientific Life: Papers in Honor of Professor Dr. Teuku Jacob (pp. 25-39). Yogyakarta, Indonesia: Bigraf Publishing.

Argue, D., Donlon, D., Groves, C., \& Wright, R. (2006). Homo floresiensis: Microcephalic, Pygmoid, Australopithecus, or Homo? Journal of Human Evolution, 51, 360-374. http://dx.doi.org/10.1016/j.jhevol.2006.04.013

Ascenzi, A., Mallegni, F., Manzi, G., Segre, A. G., \& Segre Naldini, E. (2000). A Re-Appraisal of Ceprano Calvaria Affinities with Homo erectus, after the New Reconstruction. Journal of Human Evolution, 39, 443-450. http://dx.doi.org/10.1006/jhev.2000.0425

Ashton, E. H., \& Zuckerman, S. (1954). The Anatomy of the Articular Fossa (Fossa Mandibularis) in Man and Apes. American Journal of Physical Anthropology, 12, 29-62. http://dx.doi.org/10.1002/ajpa.1330120117

Baab, K. L. (2008). The Taxonomic Implications of Cranial Shape Variation in Homo erectus. Journal of Human Evolution, 54, 827-847. http://dx.doi.org/10.1016/j.jhevol.2007.11.003

Baab, K. L. (2012). Homo floresiensis: Making Sense of the Small-Bodied Hominin Fossils from Flores. Nature Education Knowledge, 3, 4.

Berckhemer, F. (1933). Ein Menschen-Schädel aus den diluvialen Schottern von Steinheim a.d. Murr. Anthropologischer Anzeiger, 10, 318-321.

Black, D. (1927). On a Lower Molar Hominid Tooth from the Chou Kou Tien Deposit. Palaeontologica Sinica, New Series D, No. 7, 1-28.

Blackwood, C. B., Marsh, T., Kim, S. H., \& Paul, E. A. (2003). Terminal Restriction Fragment Length Polymorphism Data Analysis-Authors' Reply. Applied and Environmental Microbiology, 69, 6342-6343.

Bookstein, F. L. (1991). Morphometric Tools for Landmark Data. Cambridge: Cambridge University Press.

Broom, R., \& Robinson, J. T. (1949). A New Type of Fossil Man. Nature, 164, 322-323. http://dx.doi.org/10.1038/164322a0

Brown, P. (2004). A New Small-Bodied Hominin from the Late Pleistocene of Flores, Indonesia. Nature, 431, $1055-1061$. http://dx.doi.org/10.1038/nature02999

Bruner, E. (2013). The Species Concept as a Cognitive Tool for Biological Anthropology. American Journal of Primatology, 75, 10-15. http://dx.doi.org/10.1002/ajp.22087

Bruner, E., \& Manzi, G. (2007). Landmark-Based Shape Analysis of the Archaic Homo Calvarium from Ceprano (Italy). American Journal of Physical Anthropology, 132, 355-366. http://dx.doi.org/10.1002/ajpa.20545

Couette, S., \& White, J. (2010). 3D Geometric Morphometrics and Missing-Data. Can Extant Taxa Give Clues for the Analysis of Fossil Primates? Imaging \& 3D in Palaeontology and Palaeoanthropology, 9, 423-433.

Curnoe, D., \& Tobias, P. V. (2006). Description, New Reconstruction, Comparative Anatomy, and Classification of the Sterkfontein Stw 53 Cranium, with Discussions about the Taxonomy of Other Southern African Early Homo Remains. Journal of Human Evolution, 50, 36-77. http://dx.doi.org/10.1016/j.jhevol.2005.07.008

Delson, E., Harvati, K., Reddy, D., Marcus, L. F., Mowbray, K., Sawyer, G. J., Jacob, T., \& Marquez, S. (2001). The Sambungmacan 3 Homo erectus Calvaria: A Comparative Morphometric and Morphological Analysis. Anatomical Record, 262, 380-397. http://dx.doi.org/10.1002/ar.1048

Depecker, M., Berge, C., Penin, X., \& Renous, S. (2006). Geometric Morphometrics of the Shoulder Girdle in Extant Turtles (Chelonii). Journal of Anatomy, 208, 35-45. http://dx.doi.org/10.1111/j.1469-7580.2006.00512.x

Dryden, I. L., \& Mardia, K. V. (1998). Statistical Shape Analysis. London: John Wiley.

Dubois, E. (1894). Pithecanthropus erectus_Eine Menschenaehnliche Ubergangsform aus Java. Batavia: Landesdruckerei.

Durband, A. (2002). Squamotympanic Fissure in the Ngandong and Sambungmacan Hominids: A Reply to Delson et al. Anatomical Record, 266, 138-141. http://dx.doi.org/10.1002/ar.10052

Durband, A. (2008). Mandibular Fossa Morphology in the Ngandong and Sambungmacan Fossil Hominids. Anatomical Record, 291, 1212-1220. http://dx.doi.org/10.1002/ar.20698 
Feibel, C. S., Brown, F. H., \& McDougall, I. (1989). Stratigraphic Context of Fossil Hominids from the Omo Group Deposits: Northern Turkana Basin, Kenya and Ethiopia. American Journal of Physical Anthropology, 78, 595-622. http://dx.doi.org/10.1002/ajpa.1330780412

Gabunia, L., Vekua, A., Lordkipanidze, D., Swisher III, C. C., Ferring, R., Justus, A., Nioradze, M., Tvalchrelidze, M., Antón, S., Bosinski, G., Joris, O., Lumley, M., Majsuradze, G., \& Mouskhelishvili, A. (2000). Earliest Pleistocene Hominid Cranial Remains from Dmanisi, Republic of Georgia: Taxonomy, Geological Setting, and Age. Science, 288, 10191025. http://dx.doi.org/10.1126/science.288.5468.1019

Godfrey, L., \& Marks, J. (1991). The Nature and Origins of Primate Species. Yearbook of Physical Anthropology, 34, 39-68. http://dx.doi.org/10.1002/ajpa.1330340605

Gordon, A. D., Nevell, L., \& Wood, B. (2008). The Homo floresiensis Cranium (LB1): Size, Scaling and Early Homo Affinities. Proceedings of the National Academy of Sciences of the United States of America, 105, 4650-4655.

http://dx.doi.org/10.1073/pnas.0710041105

Gorsuch, R. (1983). Factor Analysis (2nd ed.). Lawrence Erlbaum Associates.

Green, H., \& Curnoe, D. (2005). Mandibular fossa of Fossil Australians. Homo, 56, 233-247. http://dx.doi.org/10.1016/j.jchb.2005.06.001

Groves, C. (2001). Why Taxonomic Stability Is a Bad Idea, or Why Are There So Few Species of Primates (or Are There?). Evolutionary Anthropology, 10, 192-198. http://dx.doi.org/10.1002/evan.10005

Groves, C. P., \& Mazák, V. (1975). An Approach to the Taxonomy of the Hominidae: Gracile Villafranchian Hominids of Africa. Časopis pro mineralogii a geologii, 20, 225-247.

Grün, R. (1996). A Re-Analysis of Electron Spin Resonance Dating Results Associated with the Petralona Hominid. Journal of Human Evolution, 30, 227-241. http://dx.doi.org/10.1006/jhev.1996.0020

Gunz, P., \& Bulygina, E. (2012). The Mousterian Child from Teshik-Tash Is a Neanderthal: A Geometric Morphometric Study of the Frontal Bone. American Journal of Physical Anthropology, 149, 365-379.

http://dx.doi.org/10.1002/ajpa.22133

Hammer, Ø., Harper, D. A. T., \& Ryan, P. D. (2001). PAST: Paleontological Statistics Software Package for Education and Data Analysis. Palaeontologia Electronica, 4, 9 p. http://palaeo-electronica.org/2001_1/past/issue1_01.htm

Harvati, K. (2003). Quantitative Analysis of Neanderthal Temporal Bone Morphology Using Three-Dimensional Geometric Morphometrics. American Journal of Physical Anthropology, 120, 323-338. http://dx.doi.org/10.1002/ajpa.10122

Hatcher, L. (1994). A Step-by-Step Approach to Using the SAS® System for Factor Analysis and Structural Equation Modeling. Cary, NC: SAS Institute.

Henneberg, M., \& Thorne, A. (2004). Flores May Be Pathological Homo sapiens. Before Farming, 1, 2-4.

Hershkovitz, I., Kornreich, L., \& Laron, Z. (2007). Comparative Skeletal Features between Homo floresiensis and Patients with Primary Growth Hormone Insensitivity (Laron Syndrome). American Journal of Physical Anthropology, 134, 198208. http://dx.doi.org/10.1002/ajpa.20655

Hinton, R. J., \& Carlson, D. S. (1979). Temporal Changes in Human Temporomandibular Joint Size and Shape. American Journal of Physical Anthropology, 50, 325-334. http://dx.doi.org/10.1002/ajpa.1330500305

Holt, B., \& Benfer, R. A. (2000). Estimating Missing Data: An Iterative Regression Approach. Journal of Human Evolution, 39, 289-296. http://dx.doi.org/10.1006/jhev.2000.0418

Howells, W. W. (1980). Homo Erectus-Who, When, and Where: A Survey. Yearbook of Physical Anthropology, $23,2-23$. http://dx.doi.org/10.1002/ajpa.1330230503

Kaifu, Y., Arif, J., Yokoyama, K., Baba, H., Suparka, E., \& Gunawan, H. (2007). A New Homo erectus Molar from Sangiran. Journal of Human Evolution, 52, 222-226. http://dx.doi.org/10.1016/j.jhevol.2006.08.012

Kennedy, G. E. (1991). On the Autapomorphic Traits of Homo erectus. Journal of Human Evolution, 20, 375-412. http://dx.doi.org/10.1016/0047-2484(91)90006-H

Klein, R. G. (1994). Southern Africa before the Iron Age. In R. S. Corruccini, \& R. L. Ciochon (Eds.), Integrative Paths to the Past: Paleoanthropological Advances in Honor of F. Clark Howell (pp. 471-519). Englewood Cliffs, NJ: Prentice Hall.

Kokkoros, P., \& Kanellis, A. (1960). Découverte d’un crâne d’homme paléolithique dans la péninsule chalcidique. L'Anthropologie, 64, 132-147.

Kramer, A. (1993). Human Taxonoic Diversity in the Pleistocene: Does Homo erectus Represent Multiple Hominid Species. American Journal of Physical Anthropology, 91, 161-171.

http://dx.doi.org/10.1002/ajpa.1330910203 
Lawing, A. M., \& Polly, P. D. (2010). Geometric Morphometrics: Recent Applications to the Study of Evolution and Development. Journal of Zoology, 280, 1-7. http://dx.doi.org/10.1111/j.1469-7998.2009.00620.x

Leakey, L. S. B. (1961). New Finds at Olduvai Gorge. Nature, 189, 649-650.

Lockwood, C. A., Lynch, J. M., \& Kimbel, W. H. (2002). Quantifying Temporal Bone Morphology of Great Apes and Humans: An Approach Using Geometric Morphometrics. Journal of Anatomy, 201, 447-464.

http://dx.doi.org/10.1046/j.1469-7580.2002.00122.x

Lordkipanidze, D., Ponce de Leon, M. S., Margvelashvili, A., Rak, Y., Rightmire, G.P., Vekua, A., \& Zollikofer, C. P. E. (2013). A Complete Skull from Dmanisi, Georgia, and the Evolutionary Biology of Early Homo. Science, 342, 326-331. http://dx.doi.org/10.1126/science.1238484

Manega, P. C. (1993). Geochronology, Geochemistry, and Isotopic Study of Plio-Pleistocene Hominid Sites and the Ngorongoro Volcanic Highlands in Northern Tanzania. PhD Dissertation, Denver, CO: University of Colorado.

Martinez, I., \& Arsuaga, J. L. (1997). The Temporal Bones from Sima de los Huesos Middle Pleistocene (Sierra de Atapuerca, Spain). A Phylogenetic Approach. Journal of Human Evolution, 33, 283-318. http://dx.doi.org/10.1006/jhev.1997.0155

Morwood, M. J. et al. (2005). Further Evidence for Small-Bodied Hominins from the Late Pleistocene of Flores, Indonesia. Nature, 437, 1012-1017. http://dx.doi.org/10.1038/nature04022

Mowbray, K., Marquez, S., \& Delson, E. (2002). Mandibular Fossa of Homo erectus: A Response to Durband. Anatomical Record, 266, 142-145. http://dx.doi.org/10.1002/ar.10053

O’Higgins, P., \& Jones, N. (1998). Facial Growth in Cercocebus torquatus: An Application of Three-Dimensional Geometric Morphometric Techniques to the Study of Morphological Variation. Journal of Anatomy, 193, 251-272. http://dx.doi.org/10.1046/j.1469-7580.1998.19320251.x

Oppenoorth, W. F. F. (1932). Homo javanthropus, een Pleistocene mensch van Java. Dienst van Mijnbouw in Nederlandsch-Indie Wetenschappen, Medelingen, 20, 49-63.

Osborne, J. W., \& Costello, A. B. (2004). Sample Size and Subject to Item Ratio in Principal Components Analysis. Practical Assessment, Research \& Evaluation, 9. http://PAREonline.net/getvn.asp?v=9\&n=11

Picq, P. (1984). The Temporomandibular Joint of the Fossil Hominids of the Genus Homo of the Plio-Pleistocene of East-Africa. Comptes Rendus de l'Académie des Sciences Serie II, 298, 501-506.

Picq, P. (1990). Evolutionary Trends of the Temporomandibular Joint and Hominid Phylogeny. Comptes Rendus de l'Académie des Sciences Serie II, 310, 831-836.

Rak, Y. (1986). The Neanderthal: A New Look at an Old Face. Journal of Human Evolution, 15, 151-164. http://dx.doi.org/10.1016/S0047-2484(86)80042-2

Richtsmeier, J. T., De Leon, V. B., \& Lele, S. R. (2002). The Promise of Geometric Morphometrics. Yearbook of Physical Anthropology, 45, 63-91. http://dx.doi.org/10.1002/ajpa.10174

Rightmire, G. (1990). The Evolution of Homo erectus. Cambridge: Cambridge University Press. http://dx.doi.org/10.1017/CBO9780511525674

Rightmire, G. (1996). The Human Cranium from Bodo, Ethiopia: Evidence for Speciation in the Middle Pleistocene? Journal of Human Evolution, 31, 21-39. http://dx.doi.org/10.1006/jhev.1996.0046

Rightmire, G. P. (1984). Comparisons of Homo erectus from Africa and Southeast Asia. Courier Forschungsinstitut Senckenberg, 69, 83-98.

Rightmire, G. P. (1998). Human Evolution in the Middle Pleistocene: The Role of Homo heidelbergensis. Evolutionary Anthropology, 6, 218-227. http://dx.doi.org/10.1002/(SICI)1520-6505(1998)6:6<218::AID-EVAN4>3.0.CO;2-6

Rightmire, G. P. (2004). Brain Size and Encephalization in Early Mid-Pleistocene Homo. American Journal of Physical Anthropology, 124, 109-123. http://dx.doi.org/10.1002/ajpa.10346

Rightmire, G. P. (2013). Homo erectus and Middle Pleistocene Hominins: Brain Size, Skull Form, and Species Recognition. Journal of Human Evolution, 65, 223-252. http://dx.doi.org/10.1016/j.jhevol.2013.04.008

Rohlf, J. F., \& Slice, D. (1990). Extensions of the Procrustes Method for the Optimal Superimpostion of Landmarks. Systematic Zoology, 39, 40-59. http://dx.doi.org/10.2307/2992207

Sládek. V., Galeta, P., \& Sosna, D. (2012). Measuring Human Remains in the Field: Grid Technique, Total Station, or Micro Scribe? Forensic Science International, 221, 16-22. http://dx.doi.org/10.1016/j.forsciint.2012.03.018

Strauss, R. E., Atanassov, M. N., \& De Oliveira, J. A. (2003). Evaluation of the Principal-Component and Expectation-Maximization Methods for Estimating Missing Data in Morphometric Studies. Journal of Vertebrate Palaeontology, 23, 284-296.

Stringer, C. B. (1984). The Definition of Homo erectus and the Existence of the Species in Africa and Asia. Courier Forschungsinstitut Senckenberg, 69, 131-143.

Stringer, C. B., Howell, F. C., \& Melentis, J. K. (1979). Significance of the Fossil Hominid Skull from Petralona, Greece. 
Journal of Archaeological Sciences, 6, 235-253. http://dx.doi.org/10.1016/0305-4403(79)90002-5

Susman, R. L., \& de Ruiter, D. J. (2004). New Hominin First Metatarsal (SK 1813) from Swartkrans. Journal of Human Evolution, 47, 171-181. http://dx.doi.org/10.1016/j.jhevol.2004.06.005

Tattersall, I. (1986). Species Recognition in Human Paleontology. Journal of Human Evolution, 15, 165-175. http://dx.doi.org/10.1016/S0047-2484(86)80043-4

Tattersall, I., \& Mowbray, K. (2005). Species and Paleoanthropology. Theory Bioscience, 123, 371-379. http://dx.doi.org/10.1016/j.thbio.2004.10.001

Terhune, C. E. (2011). Dietary Correlates of Temporomandibular Joint Morphology in New World Primates. Journal of Human Evolution, 61, 583-596. http://dx.doi.org/10.1016/j.jhevol.2011.08.003

Terhune, C. E. (2013). Dietary Correlates of Temporomandibular Joint Morphology in the Great Apes. American Journal of Physical Anthropology, 150, 260-272. http://dx.doi.org/10.1002/ajpa.22204

Terhune, C. E., Kimbel, W. H., \& Lockwood, C. A. (2007). Variation and Diversity in Homo erectus: A 3D Geometric Morphometric Analysis of the Temporal Bone. Journal of Human Evolution, 53, 41-60. http://dx.doi.org/10.1016/j.jhevol.2007.01.006

Trinkaus, E. (1990). Cladistics and the Hominid Fossil Record. American Journal of Physical Anthropology, 83, 1-11. http://dx.doi.org/10.1002/ajpa.1330830102

Trinkaus, E. (2003). Neandertal Faces Were Not Long; Modern Human Faces Are Short. Proceedings of the National Academy of Sciences of the United States of America, 100, 8142-8145. http://dx.doi.org/10.1073/pnas.1433023100

Ward, J. H. (1963). Hierarchical Grouping to Optimize an Objective Function. Journal of the American Statistical Association, 58, 236-244. http://dx.doi.org/10.1080/01621459.1963.10500845

Weidenreich, F. (1940). Some Problems Dealing with Ancient Man. American Anthropoloist, 42, 115-123. http://dx.doi.org/10.1525/aa.1940.42.3.02a00010

Weidenreich, F. (1943). The Skull of Sinanthropus pekinensis: A Comparative Study on a Primitive Hominid Skull. Palaeontologica Sinica, New Series D, No. 10, 43-52.

Wish-Baratz, S., Hershkovitz, I., Arensburg, B., Latimer, B., \& Jellema, L. M. (1996). Size and Location of the Human Temporomandibular Joint. American Journal of Physical Anthropology, 101, 387-400. http://dx.doi.org/10.1002/(SICI)1096-8644(199611)101:3<387::AID-AJPA7>3.0.CO;2-W

Wood, B. (1984). The Origins of Homo erectus. Courier Forschungsinstitut Senckenberg, 69, 99-111.

Woodward, A. S. (1921). A New Cave Man from Rhodesia, South Africa. Nature, 108, 371-372. http://dx.doi.org/10.1038/108371a0

Wu, X. (1981). A Well-Preserved Cranium of an Archaic Type of Early Homo sapiens from Dali, China. Scientia Sinica, 24, 530-539. 